\title{
¿QUÉ AUTORES DE COMEDIAS TRABAJARON EN EL COLISEO DEL BUEN RETIRO EN SU ÉPOCA DE ESPLENDOR (1650-1660)? ${ }^{1}$
}

\author{
Francisco Sáez Raposo \\ Universidad Complutense de Madrid \\ f.saez@,filol.ucm.es
}

\section{RESUMEN}

El Coliseo del Buen Retiro, el espacio teatral cortesano más importante de la España aurisecular, vivió su momento de máximo esplendor durante de la década de 1650, tras el enlace matrimonial entre Felipe IV y Mariana de Austria. En esa época se llevaron a cabo allí los montajes más espectaculares de la mano de dramaturgos como Pedro Calderón de la Barca y Antonio de Solís y escenógrafos como Baccio del Bianco y Antonio María Antonozzi. Aunque disponemos de muchísima información relativa a los actores y actrices que actuaron en aquellas representaciones, no se ha prestado atención a los autores de comedias, esto es, a los directores de compañía de cómicos que estuvieron a cargo, junto con los dramaturgos y los escenógrafos, de la realización de aquellos fastuosos espectáculos. En el presente trabajo se intentará elaborar el registro más preciso de aquellos profesionales a los que se encomendó esa responsabilidad y que, precisamente por las exigencias propias de esos montajes, se convertirían en los más destacados de aquellos años.

PALABRAS CLAVE: Coliseo; Buen Retiro; teatro cortesano; autor de comedias; actor.

\section{WHAT THEATER COMPANY DIRECTORS WORKED IN THE BUEN RETIRO COLISEUM IN ITS TIME OF SPLENDOR (1650-1660)?}

\begin{abstract}
The Buen Retiro Coliseum, the most important courtly theatrical space in Golden Age Spain, experienced its moment of maximum splendor during the 1650s, after the marriage between Felipe IV and Mariana of Austria. At that time, the most

\footnotetext{
${ }^{1}$ El presente trabajo ha sido realizado en el marco del proyecto PGC2018-098699-B-I00, titulado Fiestas teatrales en el Coliseo del Buen Retiro (1650-1660): Catalogación, estudio, edición crítica y recreación virtual.
} 
spectacular productions were carried out there by playwrights such as Pedro Calderón de la Barca and Antonio de Solís and stage designers such as Baccio del Bianco and Antonio María Antonozzi. Even though we have a lot of information regarding the actors and actresses who acted in those performances, no attention has been paid to company directors who were in charge, along with the playwrights and stage designers, of the production of those lavish shows. In this paper, I will try to elaborate the most accurate list of those professionals who were entrusted with this responsibility and who, precisely because of the inherent challenges of these shows, would become the most outstanding of those years.

KEYWORDS: Coliseo; Buen Retiro; Courtly theater; Company director; actor.

Desde el punto de vista de la práctica teatral cortesana en España, la década de 1640 comenzó con la inauguración del Coliseo del Buen Retiro, que tuvo lugar el 4 de febrero de ese año con la representación de Los bandos de Verona, comedia de Francisco de Rojas Zorrilla. Se ponía en funcionamiento el que llegaría a ser en muy poco tiempo el espacio áulico por antonomasia en la España aurisecular y uno de los más importantes de Europa. Había sido diseñado por el ingeniero y escenógrafo italiano Cosimo Lotti, que se planteó como objetivo dotar a la corte madrileña de un espacio teatral que respondiera a las necesidades técnicas y creativas que pudieran plantear los montajes teatrales más exigentes, al estilo de los espectáculos de aparato que se estaban llevando a cabo en la corte ducal de Toscana desde hacía aproximadamente medio siglo. No en vano, Lotti, que llegó a Madrid contratado por el Conde Duque de Olivares para proporcionar un espacio de esparcimiento para el rey, había sido discípulo de Giulio Parigi que, a su vez, lo había sido del pintor, escultor y arquitecto Bernardo Buontalenti, cuyo maestro de pintura había sido Giorgio Vasari.

Sin embargo, los sucesivos fallecimientos, pocos años después, de la reina Isabel de Borbón, el 6 de octubre de 1644, y el del infante Baltasar Carlos, heredero al trono de la Monarquía Hispánica, prácticamente dos años después, el 9 de octubre de 1646, detuvieron casi por completo la actividad teatral debido al periodo de luto que fue necesario guardar.

El enlace matrimonial de Felipe IV con Mariana de Austria, celebrado el 7 de octubre de 1649 en la localidad madrileña de Navalcarnero, supuso una esperanza y una ilusión para una sociedad que, tras el fallecimiento del príncipe heredero, y sin una reina que permitiera pensar en una continuación dinástica, había quedado sumida en un estado de profundo abatimiento. El entusiasmo colectivo provocado por la boda unido a una acelerada política sucesoria sustentada en los estrechos lazos de consanguinidad con los que, desde hacía más de un siglo, se habían pactado los enlaces matrimoniales de los Austrias españoles provocaron un incesante encadenamiento de embarazos y nacimientos reales que hubo que celebrar con el mayor de los boatos. En 
ocasiones, precisamente también por esos lazos de sangre, los partos comprometían la salud de la reina, por lo que sus recuperaciones eran también muy festejadas. En realidad, cualquier circunstancia se convirtió en motivo de celebración en un contexto social que ansiaba el nacimiento de un heredero que asegurara la continuidad de la Monarquía. Fueron también muy celebrados los cumpleaños de la reina. Como era tradición, el teatro constituyó el medio de materialización ideal de estas celebraciones, por lo que, cuando se retomó la actividad tras el matrimonio y el fin del periodo de luto obligado lo hizo con una especial intensidad. A ello ayudó, en el ámbito cortesano, la existencia de un espacio como el Coliseo, por un lado, y, por otro, la gran afición que la joven reina sintió por estos espectáculos, en los que encontró el entretenimiento y la distracción necesarios para sobrellevar la rígida etiqueta de una corte madrileña en la que era una extranjera. No hay que olvidar que ella, que aún no había cumplido los quince años cuando se casó, era treinta años más joven que Felipe IV.

A todo ello se sumó el azar, que hizo coincidir en el tiempo y en el espacio a dos mentes privilegiadas que colaboraron y se pusieron al servicio del espectáculo: Pedro Calderón de la Barca, imaginando argumentos que aunaban la calidad literaria con la espectacular, y el escenógrafo florentino Baccio del Bianco, que había sustituido a Lotti en 1651 tras su muerte y que, apoyándose en las posibilidades del Coliseo, convirtió en realidad los sueños escénicos de Calderón. A la fascinante relación cuasi simbiótica que desarrollaron ambos en la planificación y materialización de sus espectáculos cortesanos dedicó un artículo Rafael Maestre ${ }^{2}$ y un capítulo de su libro sobre el espectáculo teatral cortesano durante el reinado de Felipe IV María Teresa Chaves Montoya ${ }^{3}$. La década de 1650 es, por todo ello, el momento de máximo esplendor del teatro cortesano en la España del Siglo de Oro, que en su vertiente más espectacular estuvo basado en montajes de temática mitológica que incorporaron un importante componente musical. El fallecimiento de Felipe IV en 1665, con el nuevo parón de la actividad teatral que llevó aparejado, significó el final de esta época dorada. Cuando se retome la actividad ya durante el reinado de Carlos II la irresoluble crisis económica en la que estarán sumidas las arcas del Estado impondrá una política de austeridad que obligará a reestrenar obras que no necesitaban de un alto presupuesto para su montaje y que se habían compuesto en ese tramo final del reinado de Felipe IV. Muchas de ellas eran de Calderón, obviamente, pero también de Antonio de Solís, el otro gran entretenedor palaciego de la década de 1650. Es decir, la producción de obras nuevas se verá considerablemente mermada.

Poca atención se ha prestado, sin embargo, al cuarto componente sin cuyo concurso hubiera resultado imposible la consecución de aquellos espectáculos. Me refiero, claro está, al colectivo de actores y actrices. Tenemos muchos datos sobre su actividad en la corte, es cierto, especialmente proporcionados en su día por los trabajos

2 "Calderón de la Barca-Baccio del Bianco: un binomio escénico", Revista de bistoria moderna: Anales de la Universidad de Alicante, 11 (1992), 239-250, DOI: 10.14198/rhm1992.11.12. (consultado el 16 de noviembre de 2020).

3 "La «simbiosis» entre Calderón de la Barca y Baccio del Bianco: las puestas en escena de La fiera, el rayo y la piedra y Fortunas de Andrómeda y Perseo", en El espectáculo teatral en la corte del Felipe IV (Madrid: Ayuntamiento de Madrid, 2004), 171-218. 
de Shergold y Varey ${ }^{4}$ de Greer y Varey ${ }^{5}$, pero éstos aparecen de manera dispersa, siempre relacionados, como es lógico, con cuestiones derivadas de montajes concretos. Hay algún caso puntual, como el de Cosme Pérez, actor que creó y dio vida durante más de cuarenta años al personaje de Juan Rana, en el que, debido a su relevancia y a su excepcionalidad, se ha hecho hincapié en su vínculo con la práctica escénica cortesana. De hecho, la afición y el afecto que desde muy pronto se granjeó por parte de la joven reina propiciaron que durante esta década se dedicara, prácticamente en exclusividad, a participar en espectáculos áulicos para satisfacer los deseos de ésta de verle actuar. Pero el actor ya contaba con el favor del rey, pues no de otro modo se explica que acompañara a los recién casados durante la luna de miel que pasaron en El Escorial con el propósito de entretenerlos. Adoptaba, de este modo, la función de bufón ${ }^{6}$, lo que implicaba la necesidad de estar sometido de manera constante a su personaje. Ése debió de ser su primer contacto con la reina, que a partir de entonces querría disfrutar de su presencia e ingenio de manera habitual sobre los escenarios ${ }^{7}$.

Esa labor bufonesca intensificó su estrecho contacto con los monarcas. El rey, de manera sorprendente, le permitió, junto a otro actor apellidado Mexía ${ }^{8}$, acompañar en marzo de 1650 al embajador turco, que se encontraba de viaje diplomático en la corte, para visitar El Escorial, lugar con el que, como acabo de referir, Rana estaría familiarizado. El diplomático los conocería, o incluso los habría visto actuar en una representación que tuvo lugar en palacio con motivo de las fiestas de carnaval. Tal y como refiere Felipe IV en una carta que envía a doña Luisa Enríquez Manrique de Lara, Condesa de Paredes de Nava, fechada en Madrid el 7 de marzo de ese año, debió de ser el propio embajador, que era muy aficionado al teatro, quien solicitaría a los cómicos que le acompañaran en su excursión:

El Turco lo vio todo [se refiere a los espectáculos representados], que es muy amigo de comedias, y está tan bien hallado con los comediantes que habiendo ido hoy a ver El Escorial ha llevado por su camarada a Juan Rana y a otro farsante que llaman Mexía9.

El aprecio de la reina fue inmediato, y la cordialidad que debió de recibir de ella le animó a solicitar, en cuanto llegó a la corte, que favoreciera a su hija con la concesión de un puesto de trabajo en palacio que sirviera para aliviar las estrecheces

\footnotetext{
${ }^{4}$ Representaciones palaciegas: 1603-1699. Estudio y documentos (Londres: Tamesis Books, 1982).

${ }^{5}$ El teatro palaciego en Madrid: 1586-1707: estudio y documentos (Londres: Tamesis Books, 1997).

${ }^{6}$ Sobre la realidad de los bufones en la corte de los Austrias españoles, véase Fernando Bouza, Locos, enanos y hombres de placer en la Corte de los Austrias (Madrid: Temas de Hoy, 1996).

${ }^{7}$ Para la biografía de Cosme Pérez-Juan Rana, véase Francisco Sáez Raposo, Juan Rana y el teatro cómico breve del siglo XVII (Madrid: Fundación Universitaria Española, 2005), 21-62.

${ }^{8}$ María Luisa Lobato identificó a este actor con Antonio Mejía, que estuvo activo entre 1632 y 1655 : "Un actor en Palacio: Felipe IV escribe sobre Juan Rana", Cuadernos de Historia Moderna, 23 (1999), 88.

${ }^{9}$ Cito por Pérez Villanueva, Felipe IV y Luisa Enríquez. Manrique de Lara, Condesa de Paredes de Nava. Un epistolario inédito (Salamanca: Caja de Ahorros y Monte de Piedad de Salamanca, 1986), 121.
} 
económicas que padecía y favorecer, con ello, su posibilidad de encontrar marido ${ }^{10}$. El hecho de que tres años después, en 1653, Rana cediera a su hija la asignación vitalicia que le había concedido la reina a él el 26 de abril de 1651 en agradecimiento «de lo que la hace reír» me anima a pensar que no respondió favorablemente a aquella solicitud.

Durante este tramo final de su vida que trabajó para la corte formó pareja escénica en muchas ocasiones con la actriz Bernarda Ramírez, por lo que sabemos que ella fue también una asidua de estos espectáculos durante aquellos años. Por ello, y porque interpretaban a un matrimonio cómico, críticos de la talla de FernándezGuerra $^{11}$, Rennert ${ }^{12}$ o Sánchez-Arjona ${ }^{13}$ llegaron a pensar que estaban casados en la vida real.

Hay otros nombres muy conocidos dentro del mundo actoral de la segunda mitad del siglo XVII, como Antonio de Escamilla, Simón Aguado o Sebastián de Prado, que se repiten con frecuencia en la documentación conservada sobre festejos palaciegos. Pero creo que sería interesante intentar delimitar qué compañías fueron las encargadas de representar aquellos fastuosos espectáculos en el Coliseo del Buen Retiro durante esa década prodigiosa. Ése será mi objetivo en las próximas páginas, presentar un listado, aunque sea provisional, que sirva para identificar a aquellos grupos que estuvieron encomendados de materializar aquellos complicados montajes, tal vez como un paso previo a elaborar en otro trabajo un registro detallado de todos los actores y actrices que participaron en ellos. Aunque no dispongamos de información técnica fehaciente que nos permita llegar a conclusiones sobre las cualidades que deberían atesorar los cómicos que trabajaron en ese espacio tan singular, la reincidencia de un mismo conjunto de profesionales durante aquellos años no puede más que ser un indicativo de una técnica interpretativa que satisficiera el exigente dinamismo y coordinación que imponían unos argumentos trufados de mutaciones a ojos vista y de complicados efectos especiales. Creo que, aunque el capricho de la familia real impusiera la elección de los repartos que participaban en estas fiestas privilegiando su gusto y afición al criterio del dramaturgo y el escenógrafo, hay que aceptar que esos actores y actrices terminarían adquiriendo toda una serie de hábitos interpretativos acordes con estos exigentes montajes y muy diferentes a los requeridos por las condiciones de los corrales de comedias. Se trataba de dos contextos muy diferentes, tanto por las dimensiones del escenario, como por los recursos técnicos, la escenografía, la iluminación, etc. Entiendo, por tanto, que estos actores serían los más versátiles de su tiempo, los más competentes desde el punto de vista técnico a fuerza de exponerse al reto que suponía participar en estos espectáculos, a pesar de que no cumplían con los exigentes requisitos que Baccio del Bianco consideraba necesarios

\footnotetext{
${ }^{10} \mathrm{El}$ memorial, que se conserva manuscrito en la Bodleian Library de Oxford, está escrito en verso y lo componen cinco redondillas. Fue reproducido por Sáez Raposo, Juan Rana y el teatro cómico breve del siglo XVII (Madrid: Fundación Universitaria Española, 2005), 40.

11 D. Juan Ruiz de Alarcón y Mendoza (Madrid: Rivadeneyra, 1871), 379.

12 "Spanish Actors and Actresses between 1560 and 1680", Revue Hispanique, XVI (1907), 337 y 463.

13 Noticias referentes a los anales del teatro en Sevilla desde Lope de Rueda hasta fines del siglo XVII, (Sevilla: E. Rasco, 1898), 330.
} 
para desenvolverse en uno de sus montajes. Para alguien acostumbrado a los portentosos espectáculos de la corte toscana y a dar respuesta técnica a los audaces planteamientos escénicos de Calderón de la Barca, los cómicos españoles no estaban a la altura de las necesidades de estas obras. Como comenta, visiblemente contrariado, en una carta que envió a Fernando II de Medici, Gran Duque de Toscana, el 19 de julio de 1653, los actores españoles eran excesivamente estáticos, antinaturales y no hacían buen uso de la proxemia. Salían al escenario, recitaban su intervención y se marchaban, normalmente pensando que una vez terminado su texto ya no centraban la atención del espectador, por lo que enseguida le daban la espalda. Tenían tan automatizada esta conducta que no era extraño que no fueran conscientes del espacio y las distancias, por lo que tropezaban con sus compañeros de reparto, produciéndose situaciones aún más improcedentes cuando esto sucedía entre personajes antagonistas. No sólo los cómicos españoles eran demasiado indisciplinados a la hora de realizar su trabajo, en opinión de Bianco, sino contumaces en su negativa a la mejora, lo que le generó conflictos cuando quiso corregir alguno de estos vicios interpretativos ${ }^{14}$. Pensaba que las limitaciones técnicas de nuestros cómicos no eran merecedoras de la perfección de su trabajo escenográfico. Todo esto afeaba enormemente unas propuestas basadas en el dinamismo, el uso combinado de recursos, la confluencia de disciplinas artísticas y la precisión:

insomma la pulitezza delle scene, la puntualità delle strade, non usa qua né è fatta per questi istrioni, anzi molti, detto che hanno i lor versi, se non si accenna che ritornino dentro, cor un voltar di schiena si intende essere dentro; abbattesi molte volte che il nemico, cercando l'altro, entre per una strada che riscontrandolo ad occhi veggenti del popolo, bada a ire come se non lo vedessi e mille altre improprietà, né è possibile il porli in buona forma ${ }^{15}$.

Quizás, como apunta Del Bianco, las capacidades de los actores españoles no fueran las idóneas para sacar todo el provecho posible a espectáculos de esta envergadura, pero creo que hay que aceptar que los elegidos habrían de ser los que más se acercaran al perfil deseado y, como he apuntado antes, la recurrencia iría generando en ellos respuestas cada vez más acordes con las dificultades que afrontaban.

Para llevar a cabo mi propósito me serviré del Diccionario biográfico de actores del teatro clásico español, proyecto dirigido por la profesora Teresa Ferrer de cuya elaboración y consecución tuve el privilegio de formar parte. Se trata de una herramienta que ya se ha demostrado muy útil para profundizar en el conocimiento no sólo de la realidad social y profesional del colectivo de cómicos durante el Siglo de Oro, sino también para buscar posibles respuestas a problemas relacionados con la autoría y cronología de algunas obras, que ha sido posible delimitar gracias al conocimiento que ahora tenemos sobre el modelo de conformación de las compañías y los repertorios de comedias de los que disponían.

14 "[...] che quando tratto di levare questa usanza poco meno che non mi crocifiggono $[\ldots]$ ".

${ }^{15} \mathrm{Al}$ igual que para el texto de la nota anterior, cito por Bacci, "Lettere inedite di Baccio del Bianco", Paragone. Rivista di arte figurativa e letteratura, 157 (1963), 72. 
Muy relevante, ha sido, por poner un único ejemplo significativo, el avance que ha proporcionado sobre el conocimiento que tenemos de la incorporación de la mujer al negocio teatral y su participación activa en la dirección de compañías. Ha permitido dar un salto cuantitativo y cualitativo a los ya lejanos y eminentemente descriptivos trabajos de Cotarelo ${ }^{16}$, a los inexactos, parciales y subjetivos de Díaz de Escobar ${ }^{17}$, así como ampliar, matizar, precisar o corroborar otros más recientes como los de Rodríguez Cuadros ${ }^{18}$, Sanz Ayán ${ }^{19}$ o De la Granja ${ }^{20}$. Al calor del Diccionario biográfico vieron la luz un considerable número de trabajos vinculados con esta temática, como los de Gadea y De Salvo ${ }^{21}$, Ferrer Valls ${ }^{22}$, González ${ }^{23}$ o Sáez Raposo ${ }^{24}$, siendo, sin duda, el más importante de todos ellos, por su extensión y exhaustividad, la excelente tesis doctoral que Mimma de Salvo defendió en la Universitat de València en el año $2006^{25}$.

Tenemos constancia de la actividad de once autores de comedias, es decir, directores de compañías de actores, durante aquella década en el Palacio del Buen Retiro. Entre todos ellos hay una mujer, Francisca Verdugo.

Resulta sorprendente que la inmensa mayoría de las noticias que aparecen vinculadas con autores de comedias que participaron en estos fastuosos espectáculos correspondan a montajes desarrollados en la segunda mitad de la década y, especialmente, durante los cuatro últimos años, entre 1657 y 1660. De hecho, hasta 1655 sólo tenemos constancia de la participación de las compañías dirigidas por cuatro directores diferentes en el entorno del Palacio del Buen Retiro, pero ninguna de ellas

16 “Actores famosos del siglo XVII. Sebastián de Prado y su mujer Bernarda Ramírez", Boletín de la Real Academia Española, II, (1915), 251-293, 425-457 y 583-621.

${ }^{17}$ Historia del teatro español: comediantes, escritores y curiosidades escénicas, vol. I (Barcelona: Montaner y Simón, 1924), 119 y 228 y siguientes.

18 "Autoras y farsantas: la mujer tras la cortina", en Mercedes de los Reyes (ed.), Actas del Seminario "La presencia de la mujer en el teatro barroco español", Cuadernos Escénicos, no 5 (Sevilla: Junta de AndalucíaConsellería de Cultura-Festival de Almagro, 1998), 35-65.

19 "Las autoras de comedias en el siglo XVII: empresarias teatrales en tiempos de Calderón", en José Alcalá-Zamora, Ernest Belenguer (coords.), Calderón de la Barca y la España del Barroco, vol. 2 (Madrid: Centro de Estudios Políticos y Constitucionales-Sociedad Estatal España Nuevo Milenio, 2001), 543579.

20 "De Manuela de Escamilla y de otras autoras de comedias", Cuadernos de Historia Moderna, 27 (2002), 217-239.

21 "Jerónima de Burgos y Pedro de Valdés: biografía de un matrimonio de representantes en la España del Seiscientos”, Diablotexto. Revista de crítica literaria, 4-5 (1997-1998), 143-176.

22 "La incorporación de la mujer a la empresa teatral: actrices, autoras y compañías en el Siglo de Oro", en F. Domínguez Matito y J. Bravo Vega (eds.), Calderón entre veras y burlas. Actas de las II y III Jornadas de Teatro Clásico de la Universidad de La Rioja (7, 8 y 9 de abril de 1999 y 17, 18 y 19 de mayo de 2000) (Logroño: Universidad de La Rioja, 2002) 139-160.

23 "Mujer y empresa teatral en la España del Siglo de Oro. El caso de la actriz y autora María de Navas”, Teatro de palabras. Revista de teatro áureo, 2 (2008), 135-158.

24 "Casos de parejas cómicas en el teatro barroco español", en Damas en el tablado. Actas de las XXXI Jornadas de Teatro Clásico de Almagro (Almagro, 1, 2 y 3 de julio de 2008), eds. Felipe B. Pedraza Jiménez, Rafael González Cañal y Almudena García González (Ciudad Real: Ediciones de la Universidad de Castilla-La Mancha, 2009) 101-109.

25 La mijer y la práctica escénica en el Siglo de Oro: La búsqueda de un espacio profesional. https://core.ac.uk/download/pdf/71008074.pdf (consultado el 16 de noviembre de 2020). 
parece haber participado en una representación realizada en su Coliseo. Fueron numerosos los espacios que en dicho entorno, pensado como un lugar de esparcimiento para el rey y su familia, dieron cabida a representaciones teatrales, reservándose las más importantes, desde el punto de vista institucional y espectacular, al Coliseo. Éste, de hecho, fue el único específicamente teatral de todo el complejo. Se terminaría convirtiendo no sólo en el teatro cortesano por antonomasia en la España del Siglo de Oro, sino en uno de los más importantes de toda Europa. En El Retiro se usaron como lugares de representación tanto estancias interiores como exteriores: los Cuartos del Rey, de la Reina o del Príncipe, los jardines, el Salón Grande, el Salón de Reinos, el Saloncete, el Saloncillo, la Sala de las Burlas, la Armería, la Pieza de las Audiencias, el estanque grande, los canales, la ermita de San Pablo, las diferentes plazas de palacio (la Plaza Grande, el Patinillo, el Patinejo) y el Jardín del Caballo. ${ }^{26}$ No siempre se especifica en la documentación conservada donde se llevó a cabo la representación, sino que en los libros de cuentas se suelen registrar gastos que se vinculan con el palacio en su conjunto. En ocasiones, esa denominación genérica puede llegar a confundirse con noticias relativas a espectáculos desarrollados en el otro espacio áulico importante en la época, el Salón Dorado del Real Alcázar, y sólo el cotejo con otro tipo de informaciones permite la distinción entre ambos. Dependiendo de la magnitud del evento que se quisiera celebrar se elegía un espacio u otro dentro del Buen Retiro. Obviamente, como he señalado, el Coliseo se reservaba para los de mayor trascendencia. En ocasiones, se preparaba la fiesta, pero el emplazamiento donde se iba a desarrollar no se decidía hasta el último momento. Esto sucedía, por ejemplo, en las celebraciones de los nacimientos reales. Cuando se acercaba el momento del parto se tenía preparada toda la logística necesaria para los festejos vinculados con el acontecimiento. Sin embargo, la acuciante necesidad de proporcionar un heredero que garantizase la sucesión a la corona hacía que la dimensión de la puesta en escena planificada variara de manera significativa dependiendo del sexo del recién nacido. A punto de dar a luz la reina, Jerónimo de Barrionuevo, en un Aviso del 28 de noviembre de 1657, recoge esta circunstancia:

Ya se están poniendo en orden las tramoyas para una comedia grande y festejo que se ordena para el parto de la Reina. Y si fuere varón, se hará en el Retiro, en el Coliseo, y si fuera hembra, en el Salón Grande de Palacio ${ }^{27}$.

Ese mismo día nació el príncipe Felipe Próspero, y tres meses después, el 27 de febrero de 1658, se estrenó en el Coliseo del Buen Retiro la obra Triunfos de Amory Fortuna, de Antonio de Solís, en calidad de evento principal de entre todos los que se organizaron con motivo de aquel jubiloso suceso. Todo ese tiempo se tardó en

${ }^{26}$ Sobre el Palacio del Buen Retiro, véase Jonathan Brown y John H. Elliot, Un palacio para el rey: el Buen Retiro y la corte de Felipe IV (Madrid: Taurus, 2003). Sobre sus espacios teatrales, véase Francisco Sáez Raposo, Todo Madrid es teatro. Los escenarios de la Villa y Corte en el Siglo de Oro (Madrid: Comunidad de Madrid, 2018), 47-48 y 110-148.

${ }_{27}$ Cito por la edición de Paz y Meliá, Avisos de D. Jerónimo de Barrionuevo (1654-1658) (Madrid: Atlas), vol. II, $119 \mathrm{~b}$. 
preparar un fastuoso montaje de cuya tramoya se encargó el escenógrafo italiano Antonio María Antonozzi, que había sustituido como escenógrafo palaciego a Baccio del Bianco tras su muerte un año antes.

A partir de estas consideraciones, y de acuerdo a la naturaleza de la obra y al contexto en el que fue representada, se puede hipotetizar sobre el espacio en el que se le dio cabida. Hasta el año 1655, por consiguiente, no conservamos noticia de qué autores trabajaron en este tipo de fiestas en el Coliseo. Por ejemplo, no es presumible que la comedia burlesca que las compañías de Diego Osorio y Antonio García de Prado representaron en el Retiro en el verano de 1650, según consta en el archivo de la Cofradía de Nuestra Señora de la Novena, se realizara allí, pues por las habitualmente escasas necesidades escenográficas que requerían este tipo de comedias se podían representar sin mayor problema en alguna de las estancias privadas de palacio, aunque, por su naturaleza, donde mejor acomodo tenían era en la Sala de las Burlas. Precisamente en el Cuarto del Rey se llevó a cabo una representación el 9 de febrero de 1651 de la comedia El montañés Juan Pascual, primer asistente de Sevilla, de Juan de la Hoz y Mota a cargo de una compañía que Rosita Subirats identifica como la de Antonio García de Prado ${ }^{28}$. Algo similar se deduce de las cinco representaciones particulares que la compañía de Adrián López llevó a cabo para el rey tanto en El Pardo como en El Retiro, cuyo formato más íntimo las destinaría a un espacio privado.

El 13 de julio de 1655 consta un pago vinculado con una representación en el Coliseo al autor de comedias Bartolomé Romero, pero, curiosamente, no corresponde a un montaje preparado por él o a uno en el que hubiera participado, sino a los honorarios que les correspondían a sus dos hijas, Luisa y Mariana, por haber colaborado, junto con algunos vecinos de Fuencarral, en una comedia que presenciaron los reyes dos días antes.

La compañía dirigida por Diego Osorio sí representó en el Coliseo el 21 de febrero de 1656 una comedia de Antonio Martínez de Meneses que formó parte de una fiesta grande con tramoyas que se había montado originalmente en el Salón del Palacio del Retiro el día anterior. Es muy probable, como apuntan Varey y Shergold, que se tratase de una obra ya representada días antes, el 16 de febrero ${ }^{29}$, fecha en la que en el mismo lugar se preparó un tipo de fiesta idéntica con obras del mismo dramaturgo. La buena acogida de la pieza propiciaría que se decidiera representar en palacio ante los miembros de los diferentes Consejos del Estado pero, esta vez, en el Coliseo, donde, como se indica en la noticia, «se mudaron las tramoyas». Por aquellas mismas fechas (en concreto, desde finales del mes de enero), la compañía dirigida por Francisca Verdugo, que habría asumido la dirección de la misma un año antes tras la muerte de su esposo, Jacinto Riquelme, había dejado de representar en los corrales públicos madrileños para ensayar y posteriormente representar en el Palacio del Buen Retiro. No sabemos el espacio concreto en el que trabajó, pero allí estuvo hasta el

\footnotetext{
28 "Contribution a l'établissement du repertoire théâtral á la cour de Philippe IV et de Charles II", Bulletin Hispanique, LXXIX (1977), 449.

${ }^{29}$ En realidad, la fecha original prevista era el 13 de febrero, pero se fue posponiendo debido a los efectos que unas fiebres cuartanas estaban causando en la salud del Marqués de Heliche y una jaqueca que sufrió la reina.
} 
Martes de Carnaval, el 29 de febrero, cuando representó con su compañía una comedia «de burlas y sainetes», lo que no anima a pensar que, al menos en esa ocasión, pisaran el escenario del Coliseo.

Aunque tampoco se especifica nada al respecto, considero que cuando la compañía de Pedro de la Rosa representó en El Retiro El golfo de las sirenas, de Pedro Calderón de la Barca, el 12 de febrero de 1657, Lunes de Carnaval, lo haría en el Coliseo debido al gran aparato de la obra. Ésta había sido estrenada en el Palacio de la Zarzuela casi un mes antes, el 17 de enero, en un montaje en el que participaron la compañía de Rosa y la de Diego Osorio. Se trató del último trabajo escenográfico de Baccio del Bianco. El grupo del primero estuvo trabajando a lo largo de ese mes de enero en otro Real Sitio, en este caso, en el Palacio de El Pardo. Aunque la de Osorio también estaba en El Retiro, no colaboró con la de su colega en el montaje allí de la zarzuela de Calderón (el 10 de febrero esta última ensayó sola), como había sucedido en su estreno, ya que hizo El alcázar secreto, de Antonio de Solís. De hecho, ambas comedias se representaron el mismo día en una intensa sesión doble, y consta que al menos a la de Calderón, que se vio por la noche, asistió el rey. Al día siguiente, la noche del Martes de Carnaval, se repitió la función, asumo que a cargo de la misma compañía y en el mismo lugar.

Un año después, entre los meses de enero y febrero de 1658, Pedro de la Rosa y su compañía participaron en las celebraciones que se organizaron en Madrid con motivo del nacimiento del príncipe Felipe Próspero. El 8 de enero representaron ante la reina en El Retiro la comedia El laberinto de amor, de Diego Gutiérrez, sin que podamos precisar el lugar exacto. Su concurso en estos fastos les tuvo muy ocupados, con constantes ensayos matutinos y vespertinos, y les impidió trabajar en los corrales públicos. El 5 de marzo, Martes de Carnaval, su compañía y la de Diego Osorio representaron allí una "fiesta grande», sin que conservemos más información al respecto, aunque, como vamos a ver un poco más abajo, los datos cruzados de los que disponemos señalan que la comedia programada era Afectos de odio y amor, de Pedro Calderón de la Barca. La magnitud de las celebraciones organizadas por el nacimiento real y, en especial, de la pompa del montaje de Triunfos de Amor y Fortuna, de Antonio Solís, la pieza central de todos los fastos, queda reflejada en una noticia que proporciona Jerónimo de Barrionuevo el 9 de enero y que, por los datos que aporta, hizo pensar a Cotarelo ${ }^{30}$, con buen criterio, que hay un error en las fechas referidas, pues la aparatosidad del montaje sólo puede corresponderse con la necesaria para esta comedia:

El día de San Blas se van los Reyes al Retiro, y a los 8 de febrero a la comedia grande, que costará 50.000 ducados, de tramoyas nunca vistas ni oídas. Entran en ella 132 personas, siendo las 42 de ellas mujeres músicas que han traído de toda España, sin dejar ninguna, Andalucía, Castilla la Nueva y Vieja, Murcia, Valencia, y entre ellas ha venido la Bezona [Francisca Bezón], muy dama de Sevilla, y la Grifona [Bernarda

30 “Actores famosos del siglo XVII. Sebastián de Prado y su mujer Bernarda Ramírez”, 615, nota 3. 
Manuela Velázquez], que se escapó de su encierro, con que la fiesta será grande y durará las Carnestolendas hasta el día de Ceniza para que todos gocemos ${ }^{31}$.

Aparte de la comedia, la fiesta teatral estuvo conformada por los entremeses de El niño caballero, el de Salta en banco y el sainete Aguardad supremos dioses, todos ellos del propio Solís. Es decir, se trató de una fiesta compuesta de manera íntegra por el dramaturgo complutense. Aunque no se especifica a qué compañías se encomendó el fastuoso montaje preparado por Antonozzi, sabemos, en buena medida, quiénes fueron los actores principales que participaron en él ${ }^{32}$ (casi todos, por cierto, fueron invitados a comer a palacio una semana antes del estreno, el 20 de febrero) y de entre todos hay dos que en aquellos años no sólo eran destacados directores de compañía, sino que tuvieron mucho protagonismo en estos festejos: Pedro de la Rosa y Diego Osorio. De hecho, como ya he señalado, sólo una semana después, las dos compañías representaron allí, en El Retiro, una «fiesta grande» con motivo de la celebración del Martes de Carnaval. También fueron los encargados, transcurridos unos meses, de representar los autos sacramentales de las fiestas del Corpus de Madrid. Es decir, fueron las dos compañías más importantes aquel año en Madrid. Por consiguiente, creo que estamos en disposición de afirmar que fueron estos dos autores de comedias y sus cómicos los encargados de poner en pie tan aparatoso espectáculo.

Había, claro está, otros directores en activo, pero a ellos se les encomendaron otras actividades teatrales menos relevantes que se desarrollaron en el complejo palaciego, aunque no en su Coliseo. El 9 de febrero las compañías dirigidas por Esteban Núñez, alias «el Pollo», y Francisco de la Calle representaron una fiesta pública en la «primera plaza del Retiro», esto es, en una de sus plazas exteriores. Por ello, no pudieron actuar en los corrales, como estaba previsto. En esa representación participaron otros dos grupos que no se especifican, aunque uno de ellos se supone que era el dirigido por Francisco García, apodado «el Pupilo». La compañía del primero estuvo trabajando en El Retiro hasta final de mes, donde actuaron ante el rey el día 23, e incluso fueron seleccionadas de ella la primera y la tercera dama para participar en otro montaje dos días después, el 25. De la Calle, a principios de enero había

31 Avisos de D. Jerónimo de Barrionuevo (1654-1658), vol. II, 149a. El propio Barrionuevo nos informa de que la Grifona, en agosto de 1654, había sido condenada a un cruel encierro incomunicado (al que llama «emparedamiento de Baeza») y, por sus palabras, se deduce que había sido motivado por su «amistad» con Íñigo Fernández de Velasco, Duque de Frías, ya que a él le iban a enviar fuera de Madrid, primero se dice que a Cataluña y luego a Orán. El propio gacetillero muestra, con ironía, sus dudas sobre el cumplimiento de la sentencia: «En la primera fiesta que haya en Palacio enviarán a por ella». Dos años después, en un aviso fechado el 4 de octubre de 1656, informaba de que la actriz, con la ayuda de un tal Estrada, se había fugado de su encierro, que estaba cumpliendo en Toledo. Sea lo que fuere lo que hubiera causado su condena, ya vemos que a comienzos de 1658 formaba parte destacada del elenco que estaba participando en el acto principal de las celebraciones que se llevaron a cabo para festejar el nacimiento del heredero real. Véase Avisos de D. Jerónimo de Barrionuevo (1654-1658), vol. I, 53, $90-91$ y 97 y vol. II, 3 .

32 Éstos fueron Bernarda Ramírez, Mariana de Borja, Juan Rana, Francisca Bezón, Simón Aguado, Mateo Godoy, Tomás de Nájera, Bernarda Manuela y Jerónimo de Heredia. 
representado en tablados callejeros con motivo de la salida que la reina hizo para visitar a la Virgen de Atocha buscando su protección, como es tradición en la familia real española. Asimismo, participó en los ensayos de las comedias que debían representarse a finales de febrero, aunque no queda del todo claro cuál de las dos compañías terminó encargándose de las representaciones que organizó el Marqués de Heliche, que era el Alcaide del Buen Retiro y, como tal, Superintendente de Festejos Reales, pues a lo largo de ese mes ambas se vieron obligadas a incumplir con los compromisos adquiridos en los corrales de comedias para estudiarlas y ensayarlas. Esto, como tendremos ocasión de ir comprobando, fue un daño colateral habitual que ocasionaba la participación de los grupos de cómicos en los festejos cortesanos.

Aunque los datos conservados sobre la actividad teatral en El Retiro a comienzos de 1658 señalan a Pedro de la Rosa y Diego Osorio como los encargados de representar el Martes de Carnaval de ese año una «fiesta grande», sabemos, gracias a una certificación notarial, que la compañía dirigida por Francisco García, alias «el Pupilo», no pudo representar La adúltera penitente, comedia escrita en colaboración por Juan de Matos Fragoso, Jerónimo de Cáncer y Agustín Moreto, en el Corral del Príncipe porque estaban ocupados ensayando Afectos de odio y amor, de Calderón de la Barca, que se iba a representar precisamente el Martes de Carnaval ante los reyes. La noticia nos plantea varias incógnitas, ya que vincula a tres compañías con un mismo montaje. Sin embargo, no era extraño que para este tipo de acontecimientos se crearan elencos ad hoc compuestos por integrantes de diferentes grupos. De hecho, el propio García se quejaba de que el 28 de febrero tres de sus actrices, Manuela de Escamilla, su hermanastra María e Isabel Gálvez, habían sido requeridas para ensayar la comedia El embustero, de los hermanos Figueroa y Córdoba, que estaba previsto que se representara el 4 de marzo en el Palacio de la Zarzuela. Una semana antes, el día 21, el Pupilo ya había mostrado su disconformidad ante la injerencia de las autoridades, pues habían querido arrebatarle a «todas las músicas» de su plantel para incorporarlas a tres montajes que estaba preparando Esteban Núñez en Palacio: El sol del Prado, que se vio el 23 de febrero, Los dos Fernandos de Austria, de Antonio Coello y Ochoa o de Juan Arias Coello o de ambos, el día 24 ó 25, y Mentir y mudarse a un tiempo, de los hermanos Figueroa y Córdoba, representada también durante esos días, sin que podamos precisar la fecha exacta. García rogó que «no se le hiciese tanto daño» privándosele de sus actrices, por lo que finalmente se decidió que sólo Manuela de Escamilla acudiese a las representaciones palaciegas. Pero al ser ella la más famosa de todas en ese momento y, además, interpretar el papel principal (el de Ángel) en la comedia que estaban representando en el corral (La devoción del Ángel de la guarda, de Juan de Matos Fragoso), obligó a el Pupilo a cambiar de obra y sustituirla por otra que terminó fracasando debido al rechazo que provocó en el público su falta de novedad. En otras palabras, a pesar de que se aceptaron parcialmente las alegaciones de García, las consecuencias prácticas fueron igual de adversas para las finanzas de la compañía.

Por lo que respecta a la representación planeada para el Martes de Carnaval, la documentación conservada es confusa, pues mientras que Cotarelo, a partir de una relación manuscrita de Luis de Ulloa y Pereira, indica que dicha función se canceló 
«por hallarse indispuesta la reina» ${ }^{33}$, Shergold y Varey dan cuenta de una certificación notarial en la que se consigna que las compañías de Rosa y Osorio dejaron de representar en los corrales madrileños para encargarse de la «fiesta grande» que se había planificado en palacio ${ }^{34}$. En realidad, no se trata de noticias incompatibles, sino que hay que pensar que todo estaba dispuesto para llevar a cabo la función pero debió de suspenderse de manera imprevista por los repentinos problemas de salud de la reina. De ese modo, no se pudo recuperar la actividad teatral programada para ese día en los corrales, donde el grupo de Rosa iba a hacer la comedia El laberinto de amor, de Francisco Manuel de Melo o de Diego Gutiérrez ${ }^{35}$, en el Corral del Príncipe, y Osorio la obra de Calderón Agradecer y no amar.

Si las noticias vinculadas con la actividad de los autores de comedias en el Buen Retiro a comienzos del año 1658 corresponden a los fastos organizados con motivo del nacimiento del príncipe Felipe Próspero, las pocas que conservamos de finales de año lo están con las celebraciones de su primer cumpleaños. Los más importantes festejos teatrales celebrados en palacio, por consiguiente, estuvieron asociados con el heredero. Si para preparar los primeros hemos visto que colaboraron las compañías de Pedro de la Rosa y Diego Osorio, para las segundas se mantendrá la de este último, a la que se sumará la de Bartolomé Romero. Por aquellas fechas, durante todo el mes de noviembre y las dos primeras semanas de diciembre, Rosa y sus cómicos estuvieron trabajando en Segovia. El día del cumpleaños del príncipe, el 28 de noviembre, las compañías de Osorio y Romero representaron en palacio la comedia de Calderón Los tres afectos de amor, piedad, desmayo y valor, que habían ensayado durante los tres días anteriores. Ello, claro está, supuso un importante perjuicio económico para el arrendador de los corrales madrileños, ya que a las pérdidas ocasionadas por la cancelación de las funciones allí previstas se sumaba la del dinero que había adelantado a la compañía de Osorio en concepto de ayuda de costa para que se desplazara a trabajar a Madrid. Tanto fue el daño ocasionado que el arrendador, en compañía de un escribano, se personó en El Retiro para verificar que efectivamente la obligación de satisfacer la voluntad real les impedía cumplir con los compromisos adquiridos con él. El día 27, víspera de la función, vieron entrar a los cómicos a las tres de la tarde y les preguntaron si iban a ensayar, a lo que éstos respondieron afirmativamente, pero no firmaron su testimonio por estar ocupados. El escribano declaró que, aunque no había podido ver dichos ensayos, había oído cantar a los actores. No contentos con esto, escribano y arrendador se personaron de nuevo el día de la función y, tal y como declaran en el certificado elaborado, los vieron entrar en El Retiro con «los instrumentos de música y vestidos». El grado de desconfianza que evidencian estas

\footnotetext{
33 Emilio Cotarelo, "Ensayo sobre la vida y obras de don Pedro Calderón de la Barca", Boletín de la Real Academia Española, IX (1922), 638.

${ }^{34}$ Norman D. Shergold y John E. Varey, Teatros y comedias en Madrid: 1651-1665. Estudio y documentos (Londres: Tamesis Books, 1973).

${ }^{35}$ En su Catálogo de autores teatrales del siglo XVII (Madrid: Fundación Universitaria Española, 2002, 349), Urzáiz incluye una comedia con este título escrita por Cervantes entre 1587 y 1606 y que para Cotarelo Valledor era la misma que La confusa, una de las favoritas del propio escritor. En opinión de Vicenta Esquerdo Sivera, la primera sería, en realidad, una refundición de la segunda.
} 
noticias no es sino una muestra palpable del importante trastorno que conllevaba la organización de unos montajes en los que, desde instancias cortesanas, se disponía libre y desconsideradamente del capital humano que atesoraban las compañías de actores. Piénsese que en muchas ocasiones ese quebranto financiero afectaba también a los grupos implicados, pues, a esas alturas del siglo, la profunda crisis económica que afectaba a la Hacienda Real demoraba de forma considerable los pagos por los servicios prestados, a veces incluso durante años. Es decir, que mientras las ganancias obtenidas por trabajar en los teatros públicos eran inmediatas (a veces, como hemos visto, incluso anticipadas, cuando la compañía era lo suficientemente importante que convenía costear su traslado hasta Madrid), a partir de la década de 1640 participar en estos festejos cortesanos implicaba una incertidumbre económica que cada vez más costaba asumir.

Aunque, como hemos comprobado, nada se especifique del espacio cortesano en el que se llevó a cabo la representación, tanto la importancia del evento (el cumpleaños del heredero a la corona), el tiempo que se dedicó a los ensayos (tres días), así como las personalidades que el escribano y el arrendador refieren que estaban allí presentes el último día de los mismos (el Marqués de Heliche, el Conde de Monterrey y un número importante de otras personalidades) me animan a pensar a que, esta vez sí, fue el Coliseo el lugar elegido.

Muy escasas, y poco concluyentes para mi propósito, son las noticias que tenemos localizadas de actividad de autores de comedias en el Palacio del Buen Retiro en los dos años finales de la década.

El 26 de abril la compañía de Diego de Osorio, a petición del Marqués de Heliche, había dejado de trabajar en el Corral del Príncipe porque había sido requerida para representar en El Retiro ante don Juan José de Austria, que un mes antes había dejado su cargo de Gobernador en los Países Bajos. Era éste hijastro del rey, habido, según la opinión popular, con la actriz María Calderón, conocida como «la Calderona». Durante los siguientes meses, una vez regresado a España, se le agasajó en palacio por la complicada gestión que durante tres años había desempeñado en aquella región sublevada. Por cierto, nada más sabemos al respecto de aquella función. El 5 de junio de 1659 la compañía que dirigían Sebastián García de Prado y Juan de la Calle ${ }^{36}$ representó allí una comedia que habían estado ensayando el día anterior en la casa de la actriz María de Prado. El hecho de que sólo se dedicase un día a su preparación parece indicar que no estaba destinada para ser montada en el Coliseo.

Entre los días 4 y 8 había estado haciendo lo propio con la comedia de Juan Bautista Diamante titulada Servir para merecer, a cuya primera sesión de ensayos asistió Calderón de la Barca. Sin embargo, el mismo día de la función, el 9 de junio, cambiaron de idea desde palacio, y mientras al grupo de Osorio se le pidió que representara en El Retiro los sainetes que acompañaban al texto de Diamante, la de Juan de la Calle y

\footnotetext{
36 Señala Cotarelo ("Actores famosos del siglo XVII. Sebastián de Prado y su mujer Bernarda Ramírez", Boletín de la Real Academia Española, III, 1916, 9) que Pedro de la Rosa decidió apartarse de la dirección de su compañía de cómicos y, a partir del 17 de marzo de 1659, tomaron las riendas de la misma Sebastián de Prado y Juan de la Calle.
} 
García de Prado hizo otra comedia que ya tenían estudiada, por lo que la función original quedó pospuesta.

En el mes de septiembre se seguían organizando representaciones teatrales en la corte para el disfrute de Juan José de Austria. El día 20 una serie de actores pertenecientes a la compañía de Jerónimo Vallejo (Antonia Aguado, María Vallejo, Teresa Garay, Polonia Vaquerano y Carlos Vallejo) participaron en una fiesta dedicada al cumpleaños de la infanta María Teresa de Austria, a la que asistió también el bastardo real.

En noviembre, de nuevo con motivo de la celebración de un cumpleaños, esta vez del príncipe, se había preparado una comedia para representar en El Retiro, de la que se encargaron las compañías de Pedro de la Rosa, Juan de la Calle y Sebastián García de Prado. A ella asistió la familia real y don Juan José de Austria. Dicha comedia finalmente no se llevó a cabo en El Retiro debido a la ausencia del Marqués de Heliche, por lo que se decidió trasladar su montaje al Real Alcázar. El hecho de que en tan poco tiempo se pudiera adaptar su montaje a un espacio como el Salón Dorado del Alcázar, que sería donde presumiblemente se representara, no anima a pensar en una complejidad escenográfica propia de las obras de aparato del Coliseo. Sí parece que lo fuera la comedia de Antonio Martínez de Meneses que tenían previsto representar la compañía de Calle y García de Prado el 22 de diciembre con motivo del cumpleaños de la reina, ya que se ensayó durante cuatro días (entre el 18 y el mismo día 22). Sin embargo, en la documentación sólo se indica que se iba a representar «en palacio», sin más detalle. Sin embargo, una indisposición de la reina impidió finalmente que se celebrase la fiesta ese día, y tampoco se hizo al siguiente, ya que el rey no tuvo a bien suspender una jornada de caza para asistir a la función.

Termina la década con la certificación, fechada el 22 de enero de 1660, de la realización de una fiesta de la zarzuela en el Buen Retiro hecha cinco días antes, el 17, por las compañías de Pedro de la Rosa y Juan de la Calle. En mi opinión, no tuvo el aparataje necesario para ser alojada en el Coliseo, ya que, según la noticia que tenemos, se decidió llevarla a cabo de manera súbita, avisando a las compañías ese mismo día. Además, el mismo espectáculo lo habían representado sólo unos días después en los corrales públicos que, como sabemos, disponían de unos medios escenográficos muy limitados. De hecho, el día 17 ambas compañías tenían previsto trabajar en cada uno de los corrales madrileños: la compañía de Calle había puesto carteles esa misma mañana anunciando su función en la Cruz de la comedia Los Esforcias de Milán, de Martínez de Meneses, y la de Rosa hizo lo propio porque tenía previsto representar en el Príncipe El niño de la Guardia, de Lope de Vega. Lógicamente, no pudieron hacerlo pues la orden de palacio llegó a la una de la tarde, les enviaron coches para buscarlos y a las tres ya estaban allí, por lo que se tuvieron que cerrar los teatros madrileños. Todo responde, una vez más, a un capricho real que los cómicos se veían obligados a satisfacer a costa de sus intereses. Aunque no lo he ido señalando en cada caso particular, todas estas injerencias en el funcionamiento de las compañías repercutieron de manera muy negativa en los intereses del arrendador de los corrales que veía irremediablemente menguado el rendimiento económico que obtenía. 
Para el montaje de las fiestas de carnaval de ese año en palacio se constituyó un grupo formado por actores seleccionados de las compañías de Pedro de la Rosa, Juan de la Calle, Sebastián García de Prado y otras, que representaron tres comedias de Calderón, entre ellas, Mujer, llora y vencerás, una de Juan de Zabaleta y doce sainetes. Las funciones tuvieron lugar entre el 8 y 10 de febrero.

Aunque son numerosas las noticias que de manera directa o indirecta han recogido la participación de actores y actrices en los montajes palaciegos organizados en el Coliseo del Buen Retiro, no son tantas las que los vinculan con directores de compañía concretos. Si bien es cierto que en muchas ocasiones esas compañías eran contingentes, esto es, formadas de manera caprichosa a partir de los integrantes más destacados de varias de ellas, a su cabeza, organizando los ensayos y todo el trabajo había siempre un responsable. Aunque la imagen visible del espectáculo la aporten los actores y las actrices que intervienen en el mismo, en última instancia, el autor de comedias o director de compañía era, junto con el dramaturgo y el escenógrafo, una de las piezas claves en el engranaje que conforma un montaje teatral. Desempeñaría la labor que ya en época contemporánea realiza un director de escena. Ningún trabajo, hasta donde yo sé, se había ocupado de arrojar luz en este sentido. Sin embargo, considero que conocer qué autores de comedias estuvieron a cargo de los montajes más exigentes de todo el Siglo de Oro español, los que se llevaron a cabo en el Coliseo del Buen Retiro durante la década de 1650, puede ayudarnos a entender mejor la materialización escénica de la obra, su transmisión y recepción contemporánea, partiendo siempre de la premisa de que un texto dramático nace ya con la semilla de su representación inserta en él. El Diccionario biográfico de actores del teatro clásico español ha vuelto a demostrar su valía como herramienta capaz de desentrañar aspectos esenciales de la actividad teatral que trascienden el valor textual de la obra. Navegando a través de la ingente cantidad de información que pone a nuestra disposición creo haber sido capaz de acotar el selecto y reducido número de directores de compañía a los que se encomendó la preparación de estos complicados montajes. De entre ellos, destacan cuatro nombres cuya recurrencia en la información conservada evidencia su relevancia profesional y, derivada de ella, su concurso en todo tipo de espectáculos palaciegos: Pedro de la Rosa, Sebastián García de Prado, Juan de la Calle y Diego Osorio. Son los nombres que en la historia del Coliseo del Buen Retiro han de ir parejos con los de Calderón de la Barca, Antonio Solís, Baccio del Bianco y Antonio María Antonozzi.

Son pocos, como hemos podido comprobar, los datos directos e inequívocos que apuntan a representaciones concretas, sin embargo, indicios indirectos (tiempos de ensayos, solicitudes de palacio para que las compañías actuaran allí, la actividad desarrollada por las mismas en fechas anteriores y posteriores, el tipo de eventos para los que se organizaba el montaje, la naturaleza de la comedia, etc.) me han permitido llegar a alguna conclusión interesante y, sobre todo, conocer mejor la actividad teatral que se desarrolló en aquel teatro tan especial. Sin duda, un mayor y mejor conocimiento de las circunstancias materiales y humanas que coadyuvaron en la materialización de los textos teatrales en aquel espacio y momento determinados ha de redundar necesariamente en una mayor comprensión no sólo de la actividad teatral cortesana durante el siglo XVII, sino también de la realidad teatral barroca en su conjunto. 


\section{REFERENCIAS BIBLIOGRÁFICAS}

Bacci, Mina, "Lettere inedite di Baccio del Bianco", Paragone. Rivista di arte figurativa e letteratura, 157 (1963), 68-77.

Barrionuevo, Jerónimo de, Avisos de D. Jerónimo de Barrionuevo (1654-1658), ed. A. Paz y Meliá (Madrid: Atlas, 1968-1969, 2 vols).

Bouza, Fernando, Locos, enanos y hombres de placer en la Corte de los Austrias (Madrid: Temas de Hoy, 1996).

Brown, Jonathan y Elliot, John H., Un palacio para el rey: el Buen Retiro y la corte de Felipe IV (Madrid: Taurus, 2003).

Chaves Montoya, María Teresa, "La «simbiosis» entre Calderón de la Barca y Baccio del Bianco: las puestas en escena de La fiera, el rayo y la piedra y Fortunas de Andrómeda y Perseo", en El espectáculo teatral en la corte del Felipe IV (Madrid: Ayuntamiento de Madrid, 2004), 171-218.

Cotarelo y Mori, Emilio, "Actores famosos del siglo XVII. Sebastián de Prado y su mujer Bernarda Ramírez", Boletín de la Real Academia Española, II, (1915), 251 293, 425-457 y 583-621; III (1916), 3-38 y 151-185.

. "Ensayo sobre la vida y obras de don Pedro Calderón de la Barca", Boletín de la Real Academia Española, IX (1922), 17-70, 163-208, 311-344, 429-470 y 605-649.

Díaz de Escobar, Narciso, Historia del teatro español: comediantes, escritores y curiosidades escénicas (Barcelona: Montaner y Simón, 1924, vol. I).

Fernández-Guerra y Orbe, Luis, D. Juan Ruiz de Alarcón y Mendoza (Madrid: Rivadeneyra, 1871).

Ferrer Valls, Teresa, "La incorporación de la mujer a la empresa teatral: actrices, autoras y compañías en el Siglo de Oro", en F. Domínguez Matito y J. Bravo Vega (eds.), Calderón entre veras y burlas. Actas de las II y III Jornadas de Teatro Clásico de la Universidad de La Rioja (7, 8 y 9 de abril de 1999 y 17, 18 y 19 de mayo de 2000) (Logroño: Universidad de La Rioja, 2002), 139-160.

(dir.), Diccionario biográfico de actores del teatro clásico español (Kassel: Reichenberger, 2008).

Gadea Raga, Alejandro y Salvo, Mimma de, “Jerónima de Burgos y Pedro de Valdés: biografía de un matrimonio de representantes en la España del Seiscientos", Diablotexto. Revista de crítica literaria, 4-5 (1997-1998), 143-176. 
González, Lola, "Mujer y empresa teatral en la España del Siglo de Oro. El caso de la actriz y autora María de Navas", Teatro de palabras. Revista de teatro áureo, 2 (2008), 135-158.

Granja, Agustín de la, "De Manuela de Escamilla y de otras autoras de comedias", Cuadernos de Historia Moderna, 27 (2002), 217-239.

Greer, Margaret Rich y Varey, John E., El teatro palaciego en Madrid: 1586-1707: estudio y documentos (Londres: Tamesis Books, 1997).

Lobato, María Luisa, "Un actor en Palacio: Felipe IV escribe sobre Juan Rana", Cuadernos de Historia Moderna, 23 (1999), 79-111.

Maestre Marín, Rafael, "Calderón de la Barca-Baccio del Bianco: un binomio escénico", Revista de historia moderna: Anales de la Universidad de Alicante, 11 (1992), 239-250. DOI: 10.14198/rhm1992.11.12. (consultado el 16 de noviembre de 2020).

Pérez Villanueva, Joaquín, Felipe IV y Luisa Enríquez Manrique de Lara, Condesa de Paredes de Nava. Un epistolario inédito (Salamanca: Caja de Ahorros y Monte de Piedad de Salamanca, 1986).

Rennert, Hugo, "Spanish Actors and Actresses between 1560 and 1680", Revue Hispanique, XVI (1907), 334-538.

Rodríguez Cuadros, Evangelina, "Autoras y farsantas: la mujer tras la cortina", en Mercedes de los Reyes (ed.), Actas del Seminario "La presencia de la mujer en el teatro barroco español”, Cuadernos Escénicos, no 5 (Sevilla: Junta de Andalucía-Consellería de Cultura-Festival de Almagro, 1998), 35-65.

Sáez Raposo, Francisco, Juan Rana y el teatro cómico breve del siglo XVII (Madrid: Fundación Universitaria Española, 2005).

"Casos de parejas cómicas en el teatro barroco español", en Damas en el tablado. Actas de las XXXI Jornadas de Teatro Clásico de Almagro (Almagro, 1, 2 y 3 de julio de 2008), eds. Felipe B. Pedraza Jiménez, Rafael González Cañal y Almudena García González (Ciudad Real: Ediciones de la Universidad de Castilla-La Mancha, 2009), 101-109.

Todo Madrid es teatro. Los escenarios de la Villa y Corte en el Siglo de Oro (Madrid: Comunidad de Madrid, 2018).

Salvo, Mimma de, La mujer y la práctica escénica en el Siglo de Oro: La búsqueda de un espacio profesional (Tesis Doctoral, Universitat de València, 2006). 
https://core.ac.uk/download/pdf/71008074.pdf (consultado el 16 de noviembre de 2020).

Sánchez-Arjona, José, Noticias referentes a los anales del teatro en Sevilla desde Lope de Rueda hasta fines del siglo XVII (Sevilla: E. Rasco, 1898).

Sanz Ayán, Carmen, "Las autoras de comedias en el siglo XVII: empresarias teatrales en tiempos de Calderón”, en José Alcalá-Zamora, Ernest Belenguer (coords.), Calderón de la Barca y la España del Barroco (Madrid: Centro de Estudios Políticos y Constitucionales-Sociedad Estatal España Nuevo Milenio, 2001, vol. 2), 543$579 .^{37}$

Shergold, Norman D. y Varey, John E., Teatros y comedias en Madrid: 1651-1665. Estudio y documentos (Londres: Tamesis Books, 1973).

Representaciones palaciegas: 1603-1699. Estudio y documentos (Londres: Tamesis Books, 1982).

Subirats, Rosita, "Contribution a l'établissement du repertoire théâtral á la cour de Philippe IV et de Charles II”, Bulletin Hispanique, LXXIX (1977), 401-479.

Urzáiz Tortajada, Héctor, Catálogo de autores teatrales del siglo XVII (Madrid: Fundación Universitaria Española, 2002).

Recibido: 13 de octubre de 2020 Aprobado: 8 de noviembre de 2020

${ }^{37} \mathrm{El}$ trabajo fue publicado de nuevo en Sanz Ayán, Carmen, Hacer escena. Capitulos de historia de la empresa teatral en el Siglo de Oro, Madrid, Real Academia de la Historia, 2013, 253-337. 